\title{
CAMINHOS FORMATIVOS DE UMA PROFESSORA INICIANTE E O CURSO DE QUALIFICAÇÃO DE PROFESSORES UFR/SEMED: DIÁLOGOS ENTRE ORIENTADORA/PROFESSORA E A ORIENTANDA/CURSISTA*
}

\author{
Júlia Alessandra Machado de Castro (SEMED/ROO) \\ Rosana Maria Martins (UFR)
}

\section{Introdução}

O início e o ingresso em qualquer profissão são carregados de ansiedade e expectativa, não seria diferente com o período iniciático à docência, em que o professor passa por situações novas e deverá pôr em prática os conhecimentos adquiridos não só na sua formação inicial como nas vivências e experiências da sua vida. Além da ansiedade e expectativa, outras sensações e sentimentos como insegurança, frustração, desorientação também podem surgir nessa fase.

Esses sentimentos aliados a falta de acolhida, acompanhamento e direcionamento específico no momento de inserção no campo de trabalho podem ocasionar adoecimento e até a desistência da profissão, haja vista que os professores iniciantes podem ainda estar confusos quanto ao seu atual status, ou seja, não são mais licenciandos, mas ainda não se sentem docentes, podendo, assim, sentir-se despreparados para passar por esse período conturbado de início na carreira profissional.

Quanto ao professor ingressante, nosso entendimento se coaduna com os teóricos que salientam que

[...] apesar de se encontrarem em situação de inserção profissional em face do ingresso em uma nova instituição, não são professores que se encontram vivenciando suas primeiras experiências no exercício da docência, traço que efetivamente os diferencia dos professores iniciantes [...]. Embora traga em sua bagagem experiências e saberes mais consolidados, ao entrar em novos contextos de trabalho o professor ingressante também vivencia processo de inserção profissional. É o que apontam alguns estudos

${ }^{*}$ DOI - 10.29388/978-65-86678-68-0-0-f.19-34 
(MARCELO GARCIA, 1999b; LIMA, 2006; GIOVANNI, GUARNIERI, 2014) [...] (CRUZ, FARIAS, HOBOLD, 2020, p. 5).

À vista disso, urge a necessidade de um olhar sensível a esses profissionais por parte das instâncias superiores com vistas à elaboração e implementação de políticas públicas e programas de acompanhamento e formação ao professor iniciante ou ingressante. No tocante à formação de professores, destacamos que nos sustentamos no ideário de Herneck e Mizukami (2004), as quais certificam que a formação é um processo continuum que ocorre ao longo da vida.

Neste artigo, focaremos o professor iniciante, por ser ele o objeto da Pesquisa de Mestrado em fase de qualificação. Importante se faz pontuar que se coaduna ao entendimento de Huberman (1992), Cavaco (1989), Gonçalves (1995) e Tardif (2008), quanto ao período iniciático da carreira docente, demarcado aos primeiros cinco anos de experiência docente, período esse em que os docentes estão apreendendo certas peculiaridades e características do seu trabalho, da cultura institucional do sistema de ensino e da escola na qual se inseriram.

A entrada na carreira docente é caracterizada por Huberman (1992) pelos aspectos de sobrevivência e descoberta. Em relação à sobrevivência o autor assinala que esta assemelha-se com

[...] o choque do real, a constatação da complexidade da situação profissional: o tatear constante, a preocupação consigo próprio (Estou a me aguentar?), a distância entre os ideais e as realidades cotidianas da sala de aula, a fragmentação do trabalho, a dificuldade em fazer face, simultaneamente, à relação pedagógica e à transmissão de conhecimentos, a oscilação entre relações demasiadas íntimas e demasiado distantes, dificuldades com alunos que criam problemas, com material didático etc. (HUBERMAN, 1992, p. 39, grifo do autor).

O autor expõe que o elemento da descoberta auxilia o professor iniciante durante o período de sobrevivência, dado ao "entusiasmo inicial, a exaltação por estar, finalmente, em situação de responsabilidade (ter sua sala de aula, os seus alunos, o seu programa), por se sentir num determinado corpo profissional" (HUBERMAN, 1992, p. 39). Esse sentimento de descoberta oportuniza ao professor iniciante uma certa estabilidade emocional que pode ajudá-lo a manter-se na profissão.

Para mais, o professor iniciante sofre com um "choque de realidade" (VEENMAN, 1988) em que a contradição entre o real e o ideal, por ve- 
zes, pode deixá-lo desnorteado e inseguro. Para Tardif (2008), essa constatação de que o que foi visualizado no percurso da formação inicial difere consideravelmente com o concreto vivenciado na prática em sala de aula é concebida como choque de transição, ou seja, a passagem de educando a mediador da constituição do conhecimento.

Ainda sobre o período iniciático da carreira docente e seu impacto na vida do professor iniciante, Marcelo (1999) e Tardif (2008) concordam que é um momento de mergulho em aprendizagens intensas e que o professor iniciante encontra-se em um contexto adverso permeado de tensões e dúvidas, tateando em busca da aquisição de conhecimento e competência profissional. Ademais, Tardif (2008) pontua que por mais que o professor tenha tido contato com a profissão docente durante seu processo de escolarização enquanto estudante, existem questões e aspectos compreendidos somente com o exercício da docência.

Para o autor, o docente principia suas ações mediante tentativa e erro, em que sente a necessidade de aprovação e de aceitação dos seus pares, sendo essa fase a de maior ocorrência de abandono profissional. Após algum tempo de experiência, mais ou menos após o terceiro ano de docência, o professor passa por um período de estabilização, o qual investe na sua profissão e alcança reconhecimento profissional. Realça-se que a estabilização não acontece simplesmente com o decorrer do tempo, ela é efeito das experiências vivenciadas durante a trajetória profissional influenciada pelo contexto ao qual o professor esteve inserido.

Além disso, o professor iniciante usa de variadas fontes para montar seu arcabouço de saberes profissionais, dentre eles destacam-se as experiências dos pares, os aconselhamentos, a formação contínua.

Pondera-se o não intento e suposição de que todos esses sentimentos e sensações do período iniciático da carreira pública atinjam da mesma forma e com a mesma intensidade todos os professores, sejam iniciantes ou ingressantes. Cada sujeito é tocado e atravessado de uma forma pelas experiências que passa, de acordo com sua história de vida e do ambiente ao qual faz parte.

Ao olhar para essas particularidades da fase de início da docência, é inquietante o fato de a função da coordenação pedagógica estar sendo assumida por professores iniciantes. Ressalta-se que essa inquietação não está relacionada a capacidade de execução do trabalho pedagógico, mas sim sobre o olhar que a Secretaria de Educação está direcionando para esse profissional no tocante aos aspectos de acolhimento, acompanhamento e 
formação contínua, mais especificamente, o processo formativo denominado Curso de Qualificação UFR/SEMED.

Dessa forma, este texto propõe-se discutir as relações que fomos estabelecendo entre uma Pesquisa de mestrado em curso, intitulada "Professoras iniciantes: saberes e caminhos formativos à práxis da coordenação pedagógica" e as vivências da orientadora/professora e orientanda/aluna no Curso de Qualificação, ofertado pela Universidade Federal de Rondonópolis aos Professores no final do Estágio Probatório, da Secretaria Municipal de Educação de Rondonópolis, Mato Grosso (UFR/SEMED), em 2020.

$O$ intento da pesquisa de mestrado é problematizar os aspectos que envolvem a entrada na carreira docente, período esse repleto de expectativas, dilemas e desafios para o docente que está realizando a travessia de estudante a professor, sendo mais desafiador ainda para aquele que está na travessia de professor a coordenador pedagógico.

Posto isto, nos momentos de orientações, discutiu-se sobre a inserção da cursista ao sistema educativo, as aprendizagens neste percurso, incluído o Curso de Qualificação de professores (UFR/SEMED).

\section{Diálogos entre Pesquisa de mestrado e Curso de Qualificação UFR/SEMED}

Antes de iniciarmos o diálogo sobre os entrelaçamentos entre a pesquisa de mestrado intitulada "Professoras iniciantes: saberes e caminhos formativos à práxis da coordenação pedagógica" e o Curso de Qualificação UFR/SEMED, ponderamos ser importante contextualizar as ocorrências desses dois eventos.

A pesquisa de mestrado nasceu das experiências profissionais tanto da orientanda quanto da orientadora na função da coordenação pedagógi$\mathrm{ca}$, haja vista que ambas assumiram a responsabilidade de coordenar o pedagógico da escola durante o período iniciático da carreira docente.

Aliado a isso, os estudos, as reflexões e as inquietações no que concerne ao exercício da coordenação pedagógica em fase tão inicial da carreira docente, as indagações e as perspectivas em relação ao processo formativo desse profissional e sua atuação como formador no contexto de trabalho docente serviram como propulsores para iniciar uma investigação sobre os caminhos formativos do professor iniciante coordenador pedagógico.

No tocante ao Curso de Qualificação UFR/SEMED, sua origem deuse por meio do cumprimento das normas prescritas na Lei Complementar 
$n^{\circ} 228$ de 28 de março de 2016 que dispõe sobre a reestruturação do Plano de Cargos, Carreiras e Vencimentos dos Profissionais da Educação Infantil e Fundamental do Município de Rondonópolis - MT, ora chamado de PCCV. Essa lei estabelece que a progressão horizontal da carreira docente decorrerá conforme o cargo, o nível de qualificação e a habilitação, sendo que para ascender a próxima classe, é necessário ter passado por todas as classes anteriores com prazo de três anos entre elas.

Nesse sentido, aos professores que assumiram o último concurso público para ingresso na área da educação no município de Rondonópolis, realizado no ano de 2015, com posse em meses distintos do ano de 2016, ficou determinada a realização do Curso de Qualificação para elevação de classe. A equipe responsável pela formação continuada da SEMED entrou em contato com o Curso de Pedagogia da Universidade Federal de Mato Grosso (UFMT), Campus Rondonópolis-MT (CUR) - hoje, Universidade Federal de Rondonópolis (UFR) -, no intuito de convidá-los a ministrar o Curso de Qualificação aos professores ingressantes ao Concurso de 2015, para que esses professores pudessem cumprir com o que estava em Lei e finalizar o período probatório. Na negociação da proposta do curso, o Departamento de Educação propôs que tal formação fosse ofertada em nível de Pós-graduação lato senso, já que a carga horária era bastante extensa, isto é, a determinação em forma de lei, prevê 240 horas de formação. Infelizmente, foi negada tal proposta, pela justificativa que teriam que manter o formato proposto em Lei.

Vale destacar, que os docentes vinculados ao Curso de Pedagogia da UFR pensaram e organizaram a formação dos professores da rede na compreensão de que a Universidade pública é um espaço de produção e socialização do conhecimento e lócus de formação de professorado da educação básica do estado e do município. É importante destacar que o Curso de Pedagogia, por meio da proposta do seu Projeto PolíticoPedagógico de Curso, objetiva a construção de uma educação pública de qualidade, tendo em vista a necessidade constante de formação continuada para os docentes.

Assim, após negociação entre o gestor municipal e a equipe diretiva da Universidade Federal de Rondonópolis, foi elaborado e ofertado no ano de 2020 o Curso de Qualificação aos docentes da Educação Infantil e Anos Iniciais do Ensino Fundamental. É importante esclarecer que as temáticas e referidas cargas horárias dos módulos foram propostas pela SEMED, trazendo temas importantes ao tratar da educação pública, tais como: Gestão Democrática, Políticas Públicas e Legislação Educacional, Educação, Inclusão e 
Diversidade, Psicologia do Desenvolvimento e Escolarização, Currículo e Movimento, Avaliação Mediadora, Ensino e Metodologia da Língua Portuguesa, Ensino e Metodologia da Matemática.

É importante destacar que essa aprovação e efetivação do Curso de Qualificação foi permeado de lutas e controvérsias. Os profissionais docentes encontravam-se insatisfeitos, revoltados e ultrajados com a aprovação do PCCV, devido ao engessamento da elevação de nível para aqueles que já possuíam formação em nível de Especialização, Mestrado e Doutorado.

Foram realizadas diversas movimentações dos professores e do Sindicato (SISPMUR) em prol da retirada do termo "pré-requisito da classe anterior" e da Qualificação da Lei 228, contudo, essa batalha foi perdida e todos os docentes foram subjugados a realização do Curso para terem a oportunidade de ascender na progressão de carreira. Trazer os fatores que antecedem o curso é uma forma de deixar registrado o contexto que ele foi estruturado.

O início do Curso se deu em meio a Pandemia, momentos permeados de medo e de incertezas. Desse modo, ao reflexionar sobre os caminhos até a efetivação do Curso de Capacitação com os estudos e investigações sobre os professores iniciantes e a coordenação pedagógica, sentimos a necessidade de problematizar as circunstâncias formativas que poderiam ter sido contempladas, porém não fizeram parte dessa formação docente, especialmente ao tomar como referência o professor iniciante ou ingressante na carreira pública. Para isso, faz-se imperativo que abordemos, mesmo que brevemente, a concepção de professor ingressante e de indução à docência.

Como já salientado compreendemos os professores ingressantes segundo os preceitos de Cruz, Farias e Hobold (2020), em que esses profissionais são concebidos como àqueles que "possuem experiência docente acumulada em virtude de atuação anterior em outros contextos, seja na rede privada ou mesmo como substitutos e temporários na rede pública, tanto na Educação Básica quanto Superior" (CRUZ, FARIAS, HOBOLD, 2020, p. 5). Nessa perspectiva, os professores ingressantes se distinguem dos professores iniciantes por não estarem assumindo o exercício da docência pela primeira vez, pois que já atuaram como professores em outras situações e ambientes.

Apesar disso, os professores ingressantes, também, podem ter os mesmos sentimentos de dúvidas, ansiedade, insegurança, expectativa e dilemas que os professores iniciantes, sendo necessário oportunizar a esses docentes acolhimento e acompanhamento durante o período de inserção. 
Em relação à indução à docência, assentimos aos postulados de Wong (2004), ao afirmar que a indução à docência é

[...] um processo de formação e apoio sistemático, coerente e abrangente, que [..] [é ofertado] por 2 a 3 anos e se torna parte do programa de desenvolvimento profissional de um distrito para manter os novos professores ensinando e se aperfeiçoando no sentido de melhorar sua efetividade (WONG, 2004, p. 2).

Sendo assim, o professor iniciante ao ser inserido no campo profissional passa a receber acompanhamento e direcionamento sobre os processos institucionalizados da rede educacional e sobre suas dúvidas, angústias e dilemas acerca da sua ação docente. Esse processo de formação precisa e deve ser sistematizado e perene, ou seja, carece de amparo legal para que não seja provisório e incerto conforme a equipe que esteja à frente da gestão escolar e, principalmente, municipal.

Ressaltamos que não nos referimos as oscilações que são importantes ocorrerem em um processo formativo para que ele não se torne estanque, mas sim sobre um programa que faça parte da rede educacional e que possa dar constância ao ato de "formar, apoiar e reter novos professores e fazê-los progredir em um programa de aprendizagem ao longo da vida" (WONG, 2004, p. 3).

Soma-se a essas concepções as considerações de Marcelo (1999) sobre a formação ao docente em período iniciático na carreira servir como ponte entre o professor e seu verdadeiro contexto profissional, propiciando que o iniciante perceba o espaço escolar como fonte de aprendizagem, reflexão e problematização da prática educativa e do conhecimento.

Ao ofertar um Curso de Qualificação profissional a professores recém-inseridos na rede municipal de educação, seria importante pensar em concebê-lo com direcionamento as necessidades formativas desses docentes, ou até mesmo, com demandas gerais para quem acaba de ingressar em um contexto desconhecido. Deste modo, tal oferta do Curso de Qualificação deveria ter sido estruturado pela SEMED, a partir dos preceitos que consideram as necessidades formativas do professor iniciante e ingressante a carreira docente.

Outras questões que problematizamos são o porquê de o curso não ter sido ofertado ao longo do período probatório, já que estava previsto em Lei e, de não ter sido considerada a carga horária da formação ofertada pela SEMED, aos professores iniciantes que participam da formação aos ini- 
ciantes, fruto do programa estruturado pela Rede Municipal de Educação (RME) de Rondonópolis

Salienta-se que a RME de Rondonópolis, desde 2017, oferta uma formação para o professor iniciante. Essa formação deu-se por influência dos trabalhos efetuados pelo grupo de pesquisa InvestigAção, o qual realiza uma parceria entre Universidade e Escola por meio da realização de formação de professores iniciantes com apoio do professor experiente (coordenador pedagógico).

Segundo apontamentos de Clemente (2020), os percursos desenvolvidos para a implementação da formação continuada ao professor iniciante na RME

[...]estão imbricados ao grupo de Pesquisa InvestigAção, muitos originários do Projeto OBEDUC da Universidade Federal do Mato Grosso/CUR sob a coordenação da Professora Dr. a Simone Rocha de Albuquerque e vice coordenação da professora Rosana Maria Martins que vem ao longo destes anos de maneira aguerrida lutando para melhorar a formação continuada docente, vem destacando a importância da formação para o professor iniciante, uma formação pautada no trabalho colaborativo Universidade/Escola (CLEMENTE, 2020, p. 73).

Dessa forma, é perceptível um avanço da Rede no tocante ao olhar direcionado ao professor iniciante e a necessidade de propiciar uma formação continuada direcionada a ele. Como ressaltamos, o programa de formação ao iniciante prevê um acompanhamento longitudinal desta inserção ao universo educativo, muitas vezes desconhecido, parece não ter ocorrido com a estratégia de implementação do Curso de Qualificação.

Ressaltamos, que nossa intenção em momento algum é de questionar a qualidade do Curso de Qualificação, mas sim reflexionar sobre a possibilidade deste curso ter sido pensado a fim de atender a esse profissional que adentra no espaço escolar e, em muitos momentos vivencia desafios, dilemas, angústia, incertezas, expectativas, ansiedade e tantos outros sentimentos que permeiam o início e o ingresso a carreira profissional.

Enfatizamos que o período iniciático da carreira docente é de suma importância, visto que é nessa fase que o professor poderá compreender, problematizar, refletir, questionar e relacionar os conhecimentos constituídos durante sua formação inicial com os saberes advindos da prática educativa. Dessa forma, reafirmamos o entendimento que 
É no período de iniciação profissional que o professor se defrontará com a realidade que está posta e com contradições que nem sempre estará apto a superar. Seus conhecimentos profissionais são colocados em xeque e a postura que assume pode ir desde uma adaptação e reprodução muitas vezes pouco crítica ao contexto escolar e à prática nele existente, a uma postura inovadora e autônoma, ciente das possibilidades, dos desafios e dos conhecimentos profissionais que sustentam sua ação pedagógica (PAPI; MARTINS, 2010, p. 44).

Nesse ponto de vista, é notável que são muitos os desafios do professor iniciante e, maiores ainda, para aquele que se predispõe a assumir a função de coordenador pedagógico. Esclarecemos que compreendemos como responsabilidade do professor coordenador pedagógico a organização do trabalho pedagógico e desenvolvimento do processo formativo no contexto de trabalho. Assim, corroboramos a concepção de Padilha (2001, p. 75), sobre o coordenador ser aquele que

[...] durante $o$ ano articula a equipe pedagógica em torno de melhor cumprimento do que foi estabelecido no projeto político pedagógico, coordenando seus diversos desdobramentos em plano de curso, de currículo, de ensino ou de aula. Ele exerce uma responsabilidade de maior relevância durante todo o processo, desde a fase de organização das reuniões de planejamento das atividades pedagógicas da unidade escolar até a da execução, desenvolvimento e avaliação do projeto da escola.

Dessa forma, a formação continuada ofertada a esse profissional e os reflexos desta em sua atuação enquanto formador de professores em serviço é campo fértil para reflexão e problematização.

Pontuamos a importância de haver políticas públicas de formação continuada que possam propiciar ambientes formativos para a averiguação, análise e problematização em conjunto com o professor iniciante e com o coordenador pedagógico das necessidades formativas, visando um direcionamento mais assertivo nas abordagens e nas temáticas de formação ofertada a esses profissionais.

No entanto, a maioria das vezes ainda encontramos ofertas de formação continuada conduzida de forma descontextualizada da realidade da escola e dos professores. Gatti, Barreto e André (2011, p. 198), afirmam que "[...] de modo geral, ainda prevalece uma concepção de formação transmissiva, que se desenvolve sob a forma de palestras, seminários, oficinas, cur- 
sos rápidos [...]". Diante disso, destacamos a relevância de a formação continuada, principalmente a orientada ao professor iniciante, possibilitar o diálogo, a discussão, o estudo, a reflexão e a confrontação de experiências e vivências da formação inicial e da atuação profissional.

Sendo assim, ao propor uma formação que deverá atingir a todos os professores recém-inseridos na rede municipal de educação, é imprescindível que se leve em consideração todos os aspectos da fase e do profissional a ser atendido por essa formação.

\section{Reflexões de uma iniciante: vivência do Curso de Qualificação}

Iniciei minha trajetória docente na Educação Infantil em 2016, após obter êxito no concurso de 2015. Em 2017, me candidatei a coordenação pedagógica e fui eleita pelos meus pares, assumindo assim a função de organizar o pedagógico da escola e de promover a formação em serviço dos professores. Na época, não havia formação específica para professor iniciante no exercício da coordenação pedagógica e nem para coordenador pedagógico iniciante.

Acreditamos ser importante esclarecer o que concebemos como coordenador pedagógico iniciante, uma vez que até o momento trouxemos concepções apenas do professor iniciante e ingressante. Nesse sentido, compreendemos o coordenador pedagógico iniciante como aquele professor que assume a coordenação pedagógica pela primeira vez ou que está exercendo a função a menos de 6 anos de docência. Então, independente da experiência docente do professor, nós o consideramos iniciante na função da coordenação por ser uma função diferente da docência.

Nesse seguimento, exerci a função de professora coordenadora pedagógica por dois anos (2017 e 2018), não me candidatando mais para poder iniciar os estudos no mestrado. Como relatado anteriormente, as experiências como professora iniciante no exercício da docência e da coordenação pedagógica influenciaram a escolha da temática da pesquisa de mestrado.

O Curso de Qualificação surgiu em 2020, quando eu já havia finalizado o período probatório, já havia experienciado o trabalho em sala de aula e na coordenação pedagógica. Assim, ao trazer as temáticas trabalhadas no Curso de Qualificação ponderamos o quanto ele teria agregado a minha prática profissional. No decorrer do curso, eu relacionava as situações 
que vivenciei nesses 4 anos na rede municipal de educação com as temáticas estudadas e dialogava com minha orientadora sobre o quanto muitas das discussões poderiam ter contribuído para auxiliar-me ao enfrentamento dos desafios iniciais na profissão docente. Compartilharemos algumas reflexões e problematizações entre a orientadora/professora e orientanda/cursista do curso de Qualificação sobre alguns dos módulos.

$\mathrm{O}$ início do curso deu-se com estudos sobre políticas educacionais, em que pudemos analisar e refletir sobre as influências da legislação e políticas públicas sobre a educação básica, esse módulo me trouxe uma retomada de estudos anteriores sobre a historicidade/percurso da educação básica e da educação infantil, como etapa inicial da educação básica, em que há a necessidade de um profissional docente no atendimento as crianças de zero a 5 anos.

O segundo e último módulos trataram sobre a educação especial e a diversidade, tema muito importante e significativo, principalmente pelo aumento da demanda de atendimento de crianças com deficiência e a importância de compreender o que realmente é inclusão. Para um professor iniciante, assumir uma sala de aula pela primeira vez já é um desafio, sendo maior ainda com uma pessoa com deficiência (PcD). Ressaltamos que entendemos que todas as crianças possuem suas peculiaridades no processo de aprendizagem e cabe ao professor ter 0 olhar e a escuta sensíveis para tentar atender a todas em suas especificidades. Contudo, um PcD pode requerer outros direcionamentos pedagógicos, estruturais e de pessoal especializado.

Nessa perspectiva, por meio das leituras propostas nessas disciplinas, foi possível perceber e é importante destacar que a inclusão não é tida somente para a pessoa com deficiência, mas sim para todos os estudantes. Cada educando possui sua especificidade e necessidade e corroboramos o ideário de que

Compreender e trabalhar a diversidade, conduzindo os alunos pelos caminhos da aprendizagem, e incluindo-os socialmente através do diálogo, constituem o desafio maior da pedagogia contemporânea. Não se trata, apenas, o que não seria pouco, de acolher e integrar estas crianças e estes jovens; trata-se de conseguir que eles adquiram os instrumentos do pensamento e da cultura [...] (NÓVOA, 2014, p. 44).

A promoção de práticas pedagógicas inclusivas que evidenciam as potencialidades do estudante, que atendam sua fragilidade com vista a me- 
Ihorias, precisam permear o trabalho docente, especialmente as metodologias utilizadas para o avanço deste educando em seu processo educativo. Toda perspectiva de inclusão deve estar contida no Projeto Político Pedagógico (PPP) da escola e embasada teoricamente. Acreditamos que assim, podemos caminhar para a efetivação de inclusão escolar de verdade.

No tocante ao terceiro módulo que versou sobre a avaliação mediadora, percebemos o quanto essa temática teria contribuído com a demanda recorrente nos espaços educativos, especialmente pelo do professor iniciante, uma vez que a prática educativa impõe desafios durante todo o percurso profissional dos professores, dentre estes desafios está a avaliação dos educandos.

$O$ ato de avaliar deve estar articulado ao ato de se despir de julgamentos pessoais e comportamentais, a fim de que seja um dispositivo analítico das ações educativas, para tanto, esse ato requer um "rigor científico e técnico" (LUCKESI, 1988, p. 80). Nesse sentido, no viés da avaliação mediadora, o educando torna-se o centro das ações pedagógicas e a avaliação mais um instrumento metodológico para auxiliar o professor a constatar como seus fazeres educativos refletiram nas aprendizagens dos educandos (HOFFMANN, 1994).

Dessa forma, os diálogos, problematizações e reflexões sobre a avaliação mediadora em muito contribuiriam com as dúvidas e dilemas do professor iniciante frente ao olhar avaliativo e sua estruturação.

A partir das leituras do módulo Currículo, fiquei refletindo sobre onde minhas ações pedagógicas estão ancoradas. Quais são minhas concepções de educação, escola, criança, estudante, docente? Como percebo as políticas educacionais e como as implementou em sala de aula? A leitura do texto de Macedo (2015) adicionou-se a outras leituras e reflexões em torno da Base Nacional Comum Curricular (BNCC) e a fala da autora sobre o sujeito da educação ser "singular, que o desejo do controle é matar o sujeito ou, pelo menos, suas possibilidades de responder de formas diversas à sujeição inevitável" (MACEDO, 2015, p. 903), me fez pensar se minhas ações dentro da sala de referência com as crianças de 4 anos (turma em que estou lotada esse ano) estão propiciando o controle, a poda ou a emancipação e a autonomia.

Como a própria Macedo $(2015$, p. 903$)$ expõe "O fato de o controle estar fadado ao fracasso, posto que nenhum controle satura tudo à sua volta, não nos exime de combatê-lo". Essa leitura suscitou em mim muitas indagações. De que forma estou combatendo as concepções e o cerceamento que tais políticas promovem? Até que ponto percebo isso nas práticas pe- 
dagógicas dentro da sala? São reflexões importantes a serem realizadas e que muitas vezes não fazemos.

Muitas outras reflexões realizei, em todos os módulos questionava o quanto teria sido importante ter participado de momentos como o que vivi no Curso de Qualificação, ao longo do período probatório. As temáticas discutidas, os textos estudados, as palestras que participamos, os filmes que assistimos, as trocas nos fóruns, chats e em todos momentos, foram fontes de aprendizagem colaborativa, de partilha, de entusiasmo e muitas vezes, permeados pelo cansaço causado pelo trabalho home office, pelas rotinas domésticas, pelas reuniões do grupo de pesquisa InvestigAção, pelo estágio docente no ensino superior, acompanhando a orientadora nas aulas de Didática da UFR e outras tantas situações vividas por nós.

\section{Conclusões inconclusas}

À vista de todo esse processo de problematização e reflexão sobre o período iniciático da carreira docente, o Curso de Qualificação UFR/SEMED e nossas vivências frente ao estudo desta temática que nos instiga à pesquisa, evidenciamos que a formação contínua docente é o espaço para a troca de saberes, experiências, projetos profissionais e está vinculada a todos os atores envolvidos na educação, profissionais da educação, gestores, professores, Secretaria de Educação, sendo codependentes da vontade política dos dirigentes, dos recursos econômicos e da competência dos sistemas educacionais.

Nessa perspectiva, salientamos a importância do olhar para o perfil e contexto dos profissionais que farão parte da formação ofertada, para que esta possa aproximar-se ao máximo das necessidades formativas do público atendido. Ressaltamos que o Curso de Qualificação UFR/SEMED muito contribuiu com a nossa formação. A seriedade de todos os envolvidos no processo, o apoio teórico, pessoal que recebemos ao longo do curso nos instiga a sempre buscar novos conhecimentos. Podemos afirmar que não compactuamos com a exigência da Lei e como foi aprovada, estabelecendo que a progressão horizontal da carreira docente decorrerá conforme o cargo, o nível de qualificação e a habilitação, em que para se ascender a próxima classe, é necessário ter passado por todas as classes anteriores com prazo de três anos entre elas. Nosso desejo é que possamos corrigir essa arbitrariedade e que cursos que pensem no professor iniciante e/ou ingressante na carreira docente considerem como foco principal as necessi- 
dades formativas dos mesmos e se torne uma política pública de indução à docência.

\section{Referências}

CAVACO, M. H. Ser professor: fases da vida e percursos. Um contributo para o estudo da condição do professor do ensino secundário. 1989. Dissertação (Mestrado em Educação) - Departamento de Educação da Faculdade de Ciências de Lisboa, Lisboa, 1989.

\section{CLEMENTE, Adriana dos Reis. Inserção e Indução à docência no Mato} Grosso: percepções de professores iniciantes em narrativas. 2020. Dissertação (Mestrado em Educação) - Universidade Federal de Mato Grosso, Rondonópolis, MT, 2020.

CRUZ, Giseli Barreto da; FARIAS, Isabel Maria Sabino de; HOBOLD, Márcia de Souza. Indução profissional e o início do trabalho docente: debates e necessidades. Dossiê: "Formação e inserção profissional de professores iniciantes: conceitos e práticas". Revista Eletrônica de Educação, v.14, 1-15, e4149114, jan./dez. 2020.

GATTI, Bernadete Angelina.; BARRETO, Elba Siqueira de Sá; ANDRÉ, Marli Eliza Dalmazo de Afonso. Políticas docentes no Brasil: um estado da arte. Brasília: UNESCO, 2011.

GONÇALVES, J. A. A carreira das professoras do ensino primário. In: NÓVOA, A. (ed.). Vidas de professores. Porto: Porto Editora, p. 141-169, 1995.

HERNECK, Heloisa R.; MIZUKAMI, Maria da Graça Nicoletti. Formação continuada e aprendizagem docente: reflexões sobre a implementação de uma política educacional. Revista de Ciências Humanas, v. 4, n. 1, p. 9-18, jul. 2004. Disponível em: https://www.locus.ufv.br/bitstream/handle/123456789/13124/artigo2vol4 -1.pdf? sequence=1\&isAllowed=y. Acesso em: 07 mai. 2020.

HOFFMANN, Jussara M. L. Avaliação mediadora: uma relação dialógica na construção do conhecimento. São Paulo: FDE, 1994. Disponível em: http://Itcead.nutes.ufrj.br/constructore/objetos/ideias_avaliacao_Hofman. pdf. Acesso em: 07 mai. 2020. 
HUBERMAN, M. O ciclo de vida profissional dos professores. In: NÓVOA, A. (org.) Vidas de professores. 3. Ed. Portugal: Porto Editora, 1992.

LUCKESI, Cipriano. Verificação ou avaliação: o que pratica a escola? In: V Encontro Nacional de Didática e Prática de Ensino, realizado em Belo Horizonte, em outubro de 1988. Disponível em: http://www.crmariocovas.sp.gov.br/pdf/ideias_08_p071-080_c.pdf. Acesso em: 07 mai. 2020.

MACEDO, Elizabeth. Base Nacional Comum para Currículos: direitos de aprendizagem e desenvolvimento para quem?. Educ. Soc., Campinas v. 36, n. 133, p. 891-908, out.-dez., 2015.

MARCELO GARCÍA, Carlos. Formação de professores: para uma mudança educativa. Porto: Editora, 1999.

NÓVOA, António. 0 regresso dos professores. Campo Grande: OMEP/BR/MS, 2014.

PADILHA, Paulo Roberto. Planejamento dialógico: como construir o projeto político pedagógico da escola. São Paulo: Cortez, 2001.

PAPI, Silmara de Oliveira Gomes; Martins, Pura Lúcia Oliver. A pesquisa sobre professores iniciantes: algumas aproximações. Educação em Revista. v.26, n. 03, 2010.

RONDONÓPOLIS, Lei Complementar 228 [2016]. Disponível em: https://leismunicipais.com.br/a/mt/r/rondonopolis/lei-complementar/ 2016/22/228/lei-complementar-n-228-2016-reestrutura-o-plano-de-cargoscarreiras-e-vencimentos-dos-profissionais-da-educacao-infantil-efundamental-do-municipio-de-rondonopolis-mt. Acesso em: 03 nov. 2020.

TARDIF, Maurice. Saberes docentes e formação profissional. 9. ed. Petrópolis, RJ: Vozes, 2008.

VEENMAN, Simon. El processo de llegar a ser professor? um análisis de la formación inicial. In VILLA, Alberto (coord.) Perspectivas y problemas de la función docente. Madrid - Espanha: Narcea, p. 39-68. 
WONG, H. K. Induction Programs That Keep New Teachers Teaching and Improving. NASSP Bulletin, v. 88, n. 638, March, 2004, p. 41-58. 